\title{
Characterization of Guanylate Kinase-Associated Protein, a Postsynaptic Density Protein at Excitatory Synapses That Interacts Directly with Postsynaptic Density-95/Synapse-Associated Protein 90
}

\author{
Scott Naisbitt, ${ }^{1}$ Eunjoon Kim, ${ }^{2}$ Richard J. Weinberg, ${ }^{3}$ Anuradha Rao, ${ }^{4}$ Fu-Chia Yang, ${ }^{1}$ \\ Ann Marie Craig, ${ }^{4}$ and Morgan Sheng ${ }^{1}$ \\ ${ }^{1}$ Howard Hughes Medical Institute and Department of Neurobiology, Massachusetts General Hospital and Harvard \\ Medical School, Boston, Massachussetts 02114, 2Department of Pharmacology, Pusan National University, \\ Kumjeong-ku, Pusan 609-735, South Korea, ${ }^{3}$ Department of Cell Biology and Anatomy, University of North Carolina at \\ Chapel Hill, Chapel Hill, North Carolina 27599, and ${ }^{4}$ Department of Cell and Structural Biology, University of Illinois, \\ Urbana-Champaign, Illinois 61801
}

The structure of central synapses is poorly understood at the molecular level. A recent advance came with the identification of the postsynaptic density-95 (PSD-95)/synapse-associated protein 90 family of proteins as important mediators of the synaptic clustering of certain classes of ion channels. By yeast two-hybrid screening, a novel protein termed guanylate kinaseassociated protein (GKAP) has been isolated that binds to the GK-like domain of PSD-95 (Kim et al., 1997). Here we present a detailed characterization of GKAP expression in the rat brain and report the cloning of a novel GKAP splice variant. By Northern blot, GKAP mRNAs $(4,6.5$, and $8 \mathrm{kB})$ are expressed predominantly in the rat brain. By in situ hybridization, GKAP is expressed widely in neurons of cortex and hippocampus and in the Purkinje and granule cells of the cerebellum. On brain immunoblots, two prominent bands of 95 and $130 \mathrm{kDa}$ are detected that correspond to products of short and long $\mathrm{N}$-terminal splice variants of GKAP. Two independent GKAP antibodies label somatodendritic puncta in neocortical and hippocampal neurons in a pattern consistent with synaptic elements. Immunogold electron microscopy reveals GKAP to be predominantly postsynaptic and present at asymmetric synapses and in dendritic spines. The distribution of GKAP immunogold particles is uniform in the lateral plane of the PSD but peaks in the perpendicular axis $\sim 20 \mathrm{~nm}$ from the postsynaptic membrane. In cultured hippocampal neurons GKAP immunoreactive puncta colocalize with the AMPA receptor subunit Glu receptor 1 but not with the $\mathrm{GABA}_{\mathrm{A}}$ receptor subunits $\beta 2$ and $\beta 3$. Thus GKAP is a widely expressed neuronal protein localized specifically in the PSD of glutamatergic synapses, consistent with its direct interaction with PSD-95 family proteins.

Key words: Postsynaptic density; excitatory synapse; PSD95/SAP90; immunogold electron microscopy; glutamate receptor; guanylate kinase domain; MAGUK
Proper synaptic function depends on the synaptic localization of a variety of ion channels, receptors, and signaling molecules. Synaptic targeting of these molecules is thought to be mediated by their interactions with specific intracellular anchoring or clustering proteins (for review, see Froehner, 1993; Hall and Sanes, 1993). A growing body of evidence implicates the PSD-95 family of ion channel clustering proteins as playing such a role in synaptic organization. Mammalian PSD-95 family members so far identified include Postsynaptic density-95 (PSD-95)/synapseassociated protein 90 (SAP90) (Cho et al., 1992; Kistner et al., 1993), SAP97/hdlg (Lue et al., 1994; Müller et al., 1995), chapsyn110/PSD-93 (Brenman et al., 1996b; Kim et al., 1996), and SAP102 (Müller et al., 1996). All these proteins have a common domain structure including three N-terminal PDZ domains, a central Src homology 3 domain, and a C-terminal guanylate

Received March 17, 1997; revised May 12, 1997; accepted May 13, 1997.

This work was supported by National Institutes of Health Grants NS35050 (M.S.) and NS29879 (R.W.). M.S. is an Assistant Investigator of the Howard Hughes Medical Institute. We thank Jai Up Kim for excellent technical assistance, and we are especially grateful to Ingrid K. Friberg and David G. Standaert for the in situ hybridization.

Correspondence should be addressed to Dr. Morgan Sheng, Howard Hughes Medical Institute (Wellman 423), Massachussetts General Hospital, 50 Blossom Street, Boston, MA 02114.

Copyright (C) 1997 Society for Neuroscience $0270-6474 / 97 / 175687-10 \$ 05.00 / 0$ kinase (GK) domain (Sheng, 1996). In heterologous cells and in vitro the PDZ domains in PSD-95 family members bind directly to the C-terminal ET/SDV motif of NMDA receptor and Shaker $\mathrm{K}^{+}$channel subunits, resulting in channel clustering (Kim et al., 1995, 1996; Kornau et al., 1995; Müller et al., 1996; Niethammer et al., 1996; for review, see Sheng, 1996). Loss of function mutations in Disks large (Dlg), a tumor suppressor protein, and the Drosophila homolog of the PSD-95 family of proteins (Woods and Bryant, 1991), result in abnormal synaptic morphology and loss of the normal synaptic clustering of Shaker $\mathrm{K}^{+}$channels (Lahey et al., 1994; Tejedor et al., 1997). These results support the idea that the PSD-95 family of proteins functions to cluster and localize their binding partners at synaptic junctions.

PSD-95 family members have been shown to interact with intracellular signaling molecules in addition to integral membrane proteins. PSD-95 and chapsyn-110/PSD-93 interact with the cytoplasmic enzyme neuronal nitric oxide synthase (Brenman et al., 1996a), and hdlg/SAP97 can bind to the adenomatous polyposis coli tumor suppressor protein (Matsumine et al., 1996). Thus PSD-95 family proteins may function as molecular scaffolds for coupling synaptic receptors and ion channels to downstream signaling molecules.

Recently, a novel protein, guanylate kinase-associated protein (GKAP), was identified by its interaction with the GK domain of PSD-95 using the yeast two-hybrid system (Kim et al., 1997). 
GKAP coimmunoprecipitates with PSD-95 from rat brain extracts and forms a ternary complex with PSD-95 and $\mathrm{K}^{+}$channels or NMDA receptors in heterologous cells. GKAP has a novel primary structure that includes five 14 amino acid repeats that are involved in binding to the GK domain of PSD-95 family proteins (Kim et al., 1997). Alternative splicing occurs in at least three (N-terminal, central, and C-terminal) locations in GKAP mRNA. Unfortunately, little of functional relevance can be inferred from the GKAP amino acid sequence. Furthermore, little is known about GKAP in the brain, except that it biochemically purifies in the PSD fraction (Kim et al., 1997). Understanding the physiological functions of GKAP requires a comprehensive knowledge of GKAP expression patterns in vivo. We now present a detailed characterization of GKAP expression in rat brain at both the RNA and protein levels, including electron microscopic (EM) localization of GKAP in the PSD of excitatory synapses. In addition, we describe a novel N-terminal splice variant of GKAP, $\mathrm{GKAP}_{\mathrm{L}}$, the protein product of which can account for the 130 $\mathrm{kDa}$ GKAP band seen on rat brain immunoblots previously unexplained.

\section{MATERIALS AND METHODS}

Cloning of splice variant $G K A P_{L}$. Hybridization screening of $\sim 3 \times 10^{5}$ pfu from $\lambda$ ZAP II rat cortical and hippocampal cDNA libraries (Stratagene, La Jolla, CA) using digoxigenin-labeled GKAP clone 2.1 (Kim et al., 1997) as probe and chemiluminescent detection yielded three phage clones (2.1-1, 2.1-2, and 2.1-6) that overlapped each other and GKAP clone 2.1. In addition, these clones overlapped two 5' extensions (2.1-7 and $2.1-7 \mathrm{n} 3$ ) of GKAP clone 2.1 generated by $5^{\prime}$ rapid amplification of cDNA ends (RACE) using a Marathon-Ready rat brain cDNA library (Clontech, Palo Alto, CA). Clone 2.1-2 contained an in-frame stop codon 14 codons $5^{\prime}$ of the presumed initiating methionine of $\mathrm{GKAP}_{\mathrm{L}}$. The complete intact GKAP $\mathrm{L}_{\mathrm{L}}$ coding sequence was constructed by PCR as follows: two cycles using overlapping templates as primers $[\lambda Z \mathrm{AP}$ clone 2.1-2 HindIII $2.7 \mathrm{~kb} 5^{\prime}$ fragment and GKAP clone 2.18 (Kim et al., 1997) HincII $1.4 \mathrm{~kb} \mathrm{3}$ ' fragment], followed by 28 cycles after the addition of oligonucleotide primers flanking the $\mathrm{GKAP}_{\mathrm{L}}$ coding region (including KpnI sites for subcloning).

Antibodies. Purified hexahistidine fusion proteins of nonoverlapping regions of GKAP were used to immunize rabbits (Kim et al., 1997). GKAP-N1564 antibodies were raised against GKAP $_{\mathrm{L}}$ amino acids (aa) 305-732 (clone 2.1; Kim et al., 1997), and GKAP-C9589 antibodies were raised against $\mathrm{GKAP}_{\mathrm{L}}$ aa 744-964 (clone 2.18, aa 446-666; Kim et al., 1997). GKAP-specific antibodies were purified using affinity columns (Sulfolink, Pierce, Rockford, IL) coupled with thioredoxin fusions of the respective proteins. Because both antibodies were raised against antigens containing central regions common to all GKAP splice forms, they should recognize all GKAP variants.

Expression constructs and Western blotting. GKAP expression constructs were prepared by subcloning GKAP or $\mathrm{GKAP}_{\mathrm{L}}$ into the EcoRI or $K p n I$ site, respectively, of the mammalian expression vector GW1 (British Biotechnology, Oxford, UK). COS-7 cells were transfected using the Lipofectamine method (Life Technologies, Inc., Gaithersburg, MD), and preparation and immunoblotting of COS-7 cell lysates and brain membranes were performed as described (Kim et al., 1997).

Northern and in situ hybridization. Rat poly-A mRNA Multi Tissue Northern (Clontech, Palo Alto, CA) was probed with ${ }^{32} \mathrm{P}$-labeled GKAP (clone 2.18; Kim et al., 1997) under high-stringency wash conditions and exposed $5 \mathrm{hr}$ at $-80 \mathrm{C}$ on XAR-5 (Kodak). In situ was performed on rat brain slices as described (Standaert et al., 1996), using a ${ }^{35}$ S-labeled 579 nucleotide riboprobe corresponding to GKAP amino acid $\sim 46-238$.

Immunohistochemistry on brain and cultured neurons. Immunohistochemistry on floating $50 \mu \mathrm{m}$ brain sections was performed as described (Kim et al., 1996) and visualized using the Vectastain ABC kit (Vector Labs, Burlingame, CA) and diaminobenzidine (DAB) or Cy3- or FITCconjugated secondary antibodies (Jackson ImmunoResearch, West Grove, PA). Hippocampal neuronal cultures were prepared from embryonic day 18 rats and maintained in serum-free medium above a glial monolayer as described (Banker and Cowan, 1977). Fixation and doublelabel immunostaining with GluR1 or GABA-R antibodies was performed as described (Craig et al., 1994; Kim et al., 1997) using GKAP-
$\mathrm{N} 1564$ at $1 \mu \mathrm{g} / \mathrm{ml}$. DAB brain sections and cultured hippocampal neurons were viewed using a Zeiss Axioskop microscope; fluorescent brain images were examined using a Bio-Rad MRC 1000 confocal microscope.

Electron microscopy. Male Sprague Dawley rats (200-350 gm) were anesthetized with pentobarbital $(50 \mathrm{mg} / \mathrm{kg})$ and perfused intracardially with $500 \mathrm{ml}$ of mixed aldehyde fixative (1-2.5\% glutaraldehyde/4\% paraformaldehyde) in $0.1 \mathrm{M}$ phosphate buffer, $\mathrm{pH}$ 7.4. Sections of forebrain were cut with a Vibratome and embedded without osmium according to the method of Phend et al. (1995). Briefly, 40-50 $\mu \mathrm{m}$ sections were rinsed in $0.1 \mathrm{M}$ maleate buffer (MB), $\mathrm{pH} 6.0$, incubated over ice sequentially with $1 \%$ tannic acid, $1 \%$ uranyl acetate, $0.5 \%$ iridium tetrabromide (all solutions in MB), and 1\% para-phenylene diamine (in $70 \%$ ethanol), dehydrated in graded ethanols and propylene oxide, and infiltrated overnight with Epon-Spurr resin. The next day, sections were sandwiched between strips of ACLAR plastic and polymerized $36 \mathrm{hr}$ at $60^{\circ} \mathrm{C}$. The same method was adapted for Lowicryl HM-20; sections were treated as described above until dehydration. Alcohol dehydration and resin infiltration were performed according to standard progressive lowering of temperature methods (Newman and Hobot, 1993), and UV polymerization was performed in the cold.

Chips from cerebral cortex (layers II-III) were glued onto plastic blocks, and thin sections $(\sim 100 \mathrm{~nm})$ collected on nickel mesh grids were processed for postembedding immunocytochemistry (Phend et al., 1995). Briefly, grids were washed with Tris-buffered saline, $\mathrm{pH} 7.6$, containing $0.005 \%$ Tergitol NP-10 (TBS/T), preincubated in $0.2 \%$ normal goat serum, rinsed in TBS/T, incubated overnight in primary antibody (1:3001:1000 dilution), rinsed in TBS/T, transferred to TBS/T, $\mathrm{pH} 8.2$, incubated in secondary antibody (goat anti-rabbit IgG conjugated to $18 \mathrm{~nm}$ gold particles, 1:20; Jackson ImmunoResearch, West Grove, PA), rinsed, and dried. Grids were then poststained with uranyl acetate and Sato's lead and examined with a JEOL 200CX transmission electron microscope at $80 \mathrm{kV}$. Virtually no gold particles were seen if the primary antibody was omitted from the procedure; labeling was weak if preimmune rabbit serum was substituted; labeling in this case was not selective for synapses.

To evaluate antigen distribution at synapses, grids of neocortex (layers II-III) prepared from two animals were examined. Random electron micrographs (at 20,000-40,000 $\times$ ) were taken from fields in which at least one gold particle seemed associated with a synaptic active zone. EM negatives were then digitized with a flatbed scanner at 300 dots/inch resolution. The captured images were displayed on a computer screen; all gold particles within $100 \mathrm{~nm}$ of clearly definable active zones were analyzed online using National Institutes of Health Image software. The data presented are from 84 active zones (mean length of synaptic apposition, $338 \mathrm{~nm}$; SD, $81 \mathrm{~nm}$ ). Normalized lateral distance is defined as the absolute value of [(distance from center of particle to one edge of active zone) - (distance to other edge of active zone)]/(total length of active zone).

\section{RESULTS}

\section{GKAP $_{\mathrm{L}}, \mathrm{a} \sim 130 \mathrm{kDa}$ GKAP splice variant}

On immunoblots of rat brain membranes prepared from cerebral cortex, hippocampus, or cerebellum, GKAP antibodies label protein bands at $\sim 95$ and $\sim 130 \mathrm{kDa}$ (Kim et al., 1997). Both of these bands almost certainly represent GKAP protein, because they are recognized specifically by two independent antibodies, N1564 and C9589, raised against nonoverlapping $\mathrm{N}$ - and $\mathrm{C}$-terminal regions of GKAP (Fig. 1A). The $95 \mathrm{kDa}$ band can be accounted for by the published GKAP cDNA sequence, the expression of which in heterologous cells produces a protein that comigrates with the 95 kDa brain band (Kim et al., 1997 and Fig. 1A). We were interested in determining the molecular nature of the $130 \mathrm{kDa}$ GKAP band, which cannot be explained by known GKAP cDNAs.

Five different GKAP cDNA clones were originally isolated when the GK domain of PSD-95 was used as bait in a yeast two-hybrid screen, including three $\mathrm{N}$-terminal splice variants (Kim et al., 1997). Because these clones lacked upstream stop codons, we hypothesized that the $130 \mathrm{kDa}$ immunoreactive species in rat brain might be the product of a GKAP splice variant 
$\mathbf{A}$

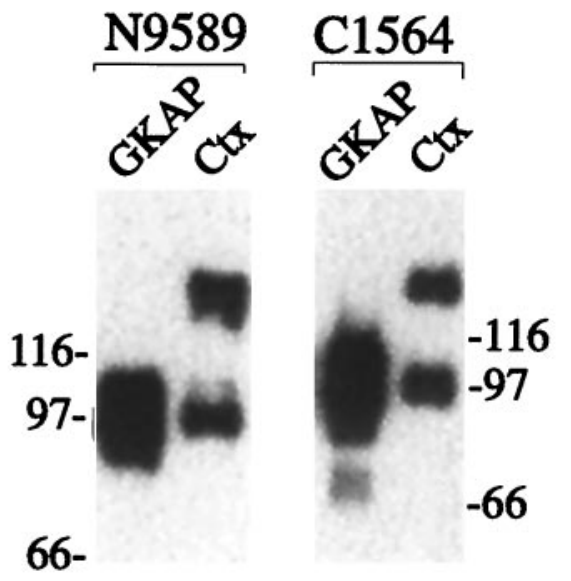

$\mathbf{C}$

rGKAP $_{L}$ MKGLSGSRSH HHGITCESAC DSLSHHSDHK PYLLSPVDHH PADHPYYTQR 50

NSFQAECVGP FSDPLASSTF PRRHYTSQQE LKDESALVPR TLATKANRLP 100

TNLLDQFERQ LPLSRDGYHT LQYKRTAVEH RSDSPGRIRH LVHSVQKLFT 150

KSHSLEGPSK GGVNGGKASP DGSQTVRYGK RSKSKERRSE PKARSNASNA 200

SPTSPSWWS DDNLDGDMCL YHTPSGVMTM GRCPDRSASQ YFMEAYNTIS 250

IGKAP $_{L}$ EQAVKASRSN NDVKCSTCAN LPVTLDAPLL KKSAWSSTLT VSRAREVYQK 300

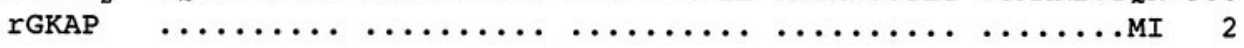

IGKAP $_{\mathrm{L}}$ ASVNMDQAVV KSEACQQERS CQYLQVPQDE WTGYTPRGKD DEIP... 344

IGKAP DLFKAEWVSS VCVQVSRNGR TDQVWVPQDE WTGYTPRGKD DEIP... 46

splice
Figure 1. Specificity of GKAP antibodies and primary structure of $\mathrm{GKAP}_{\mathrm{L}}$ $\mathrm{N}$-terminal splice variant. $A$, Two independent GKAP antibodies recognize recombinantly expressed GKAP and identical 95 and $130 \mathrm{kDa}$ bands in rat brain membranes. COS-7 cells transfected with GKAP cDNA, and rat cortical membranes $(10 \mu \mathrm{g}$ protein) were immunoblotted with GKAP antibodies N1564 and C9589, as indicated. Heterologously expressed GKAP comigrates with the $95 \mathrm{kDa}$ immunoreactive brain protein. Ctx, Cortical membranes. $B$, Comparison of heterologously expressed GKAP, GKAP $_{\mathrm{L}}$, and rat hippocampal membranes, immunoblotted with N1564 antibodies. Heterologously expressed $\mathrm{GKAP}_{\mathrm{L}}$ comigrates with the $\sim 130 \mathrm{kDa}$ immunoreactive brain protein. The same result was obtained with C9589 antibodies (data not shown). Hpc, Hippocampal membranes. $C$, Amino acid sequence alignment comparing the N-terminal GKAP splice variant $\mathrm{GKAP}_{\mathrm{L}}$ to GKAP. Splice, Presumed alternative splice site. with a longer N-terminal extension than those found in known GKAP cDNA clones.

By using both 5' RACE and conventional hybridization screening to search for $\mathrm{N}$-terminal extensions, we isolated a GKAP isoform termed $\mathrm{GKAP}_{\mathrm{L}}($ Fig. $1 C)$. GKAP $\mathrm{L}_{\mathrm{L}}$ represents the 5' extension of clone 2.1, a partial GKAP cDNA (Kim et al., 1997) described previously. When the complete GKAP $_{L}$ coding sequence was transfected into COS-7 cells, a GKAP immunoreactive polypeptide was expressed efficiently that comigrates with the $130 \mathrm{kDa}$ band seen on brain Western blots (Fig. $1 B)$. As with the shorter GKAP isoform (95 kDa), the recombinantly expressed $\operatorname{GKAP}_{\mathrm{L}}(130 \mathrm{kDa})$ is recognized by both N1564 and C9589 antibodies (Fig. $1 B$ and data not shown). Thus the GKAP described previously and the newly isolated $\mathrm{GKAP}_{\mathrm{L}}$ cDNAs can account for the 95 and $130 \mathrm{kDa}$ GKAP proteins in rat brain. It should be emphasized, however, that the alternative splicing of GKAP is complex (Kim et al., 1997); hence the 95 and $130 \mathrm{kDa}$ bands in rat brain are likely to be heterogeneous in composition with respect to GKAP splice forms.

\section{Distribution of GKAP mRNA}

A rat multitissue Northern blot probed under high-stringency conditions revealed three species of GKAP mRNA $(4,6.5$, and $8 \mathrm{kB})$ expressed predominantly in brain (Fig. 2). All three variants are also present in testis, in similar proportions, at much lower levels. The 4 and $6.5 \mathrm{kB}$ transcripts are also weakly detectable in lung. GKAP mRNA was undetectable in heart, spleen, liver, skeletal muscle, and kidney. Thus although GKAP is expressed at much higher levels in brain than in other tissues, it is not brain-specific.

In situ hybridization was used to examine the distribution of GKAP mRNA in rat brain at cellular resolution. GKAP transcripts are expressed abundantly in cortex, hippocampus, the granular layer of cerebellum, and the olfactory bulbs (Fig. 3A). GKAP mRNA is also present in lesser amounts in thalamus, the lateral septal nuclei, and several brain stem nuclei. Dark-field microscopic examination reveals GKAP mRNA expression in cells throughout all six cortical layers (Fig. 3B). In hippocampus, GKAP transcripts are abundant in the pyramidal cell somata of CA1-CA3 and in the granule cell layer of the dentate gyrus (Fig. $3 B, D)$. A population of interneurons, most conspicuous in the 

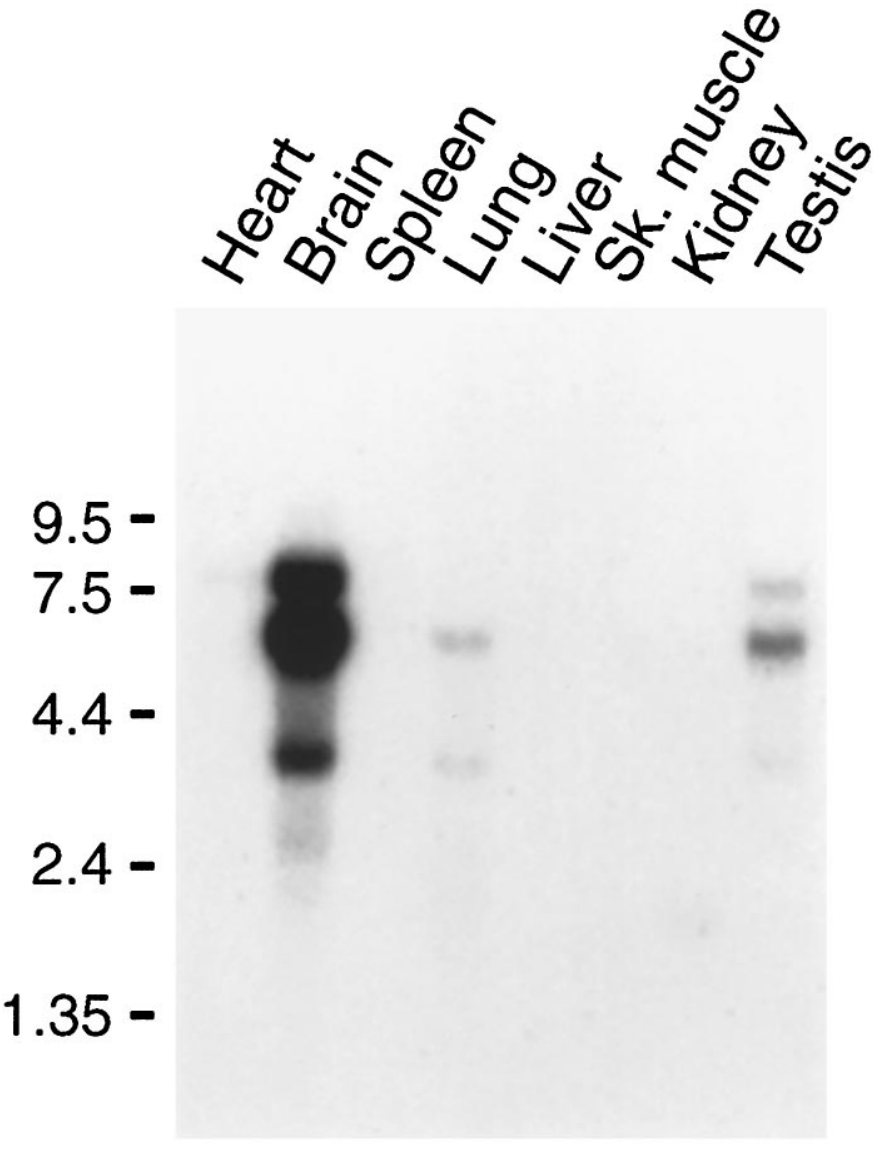

Figure 2. Tissue distribution of GKAP mRNA in rat. PolyA mRNA multitissue Northern blot probed with ${ }^{32} \mathrm{P}$-labeled GKAP DNA. Positions of RNA molecular size markers are shown.

hilus of the dentate gyrus and in the stratum (st.) oriens, are also strongly positive for GKAP mRNA. In cerebellum, GKAP transcripts are present in Purkinje and granule cells (Fig. 3C).

\section{Immunohistochemical distribution of GKAP protein in rat brain}

GKAP protein is widely expressed in neurons of rat brain in a punctate somatodendritic pattern. Similar results were obtained with both GKAP antibodies, strong evidence that the immunostaining pattern corresponds to actual GKAP distribution. Furthermore, this staining pattern was abolished by antibody preabsorption with the appropriate fusion protein antigen (data not shown). In addition, the regional and cellular distribution of GKAP immunoreactivity correlates well with the distribution of GKAP mRNA expression revealed by in situ hybridization.

In hippocampus, GKAP immunoreactivity is prominent in a population of interneurons (Fig. $4 A-C$ ) the distribution of which is strikingly reminiscent of the in situ hybridization pattern (Fig. $3 B, D)$. The interneurons in the hilus of the dentate gyrus, for example, positive for GKAP mRNA, are highly immunoreactive for the GKAP protein (Fig. 4A,C,G). The st. oriens stains darkly and contains many GKAP immunoreactive interneurons (Fig. $4 A, B$ ), again correlating with GKAP mRNA distribution (Fig. $3 B, D)$. GKAP immunoreactive interneurons are also present within and around the pyramidal cell body layer; an interneuron from area CA1 is shown at high power in Figure $4 F$. Many, although not all, of these GKAP-positive interneurons are also immunoreactive for glutamic acid decarboxylase (data not shown) and therefore presumably represent GABAergic inhibitory neurons.

The principal neurons of hippocampus also show prominent dendritic GKAP labeling. The dendritic fields of pyramidal neurons in CA1-CA3, and of dentate granule cells, are stained by both N1564 and C9589 antibodies, whereas the soma are relatively spared (Fig. 4A,B). This immunostaining pattern corroborates the presence of GKAP mRNA in these neurons and emphasizes the dendritic localization of GKAP protein. Pyramidal cell dendrites are best visualized by confocal microscopy, which shows GKAP immunoreactivity concentrated in puncta along dendrites in a pattern consistent with synaptic localization (Fig. $4 D, E)$. This is true not only in pyramidal cell dendrites, but in the brightly stained interneurons as well (Fig. $4 F, G)$. Although their staining patterns are qualitatively similar, the two independent GKAP antibodies show some quantitative differences in staining. Pyramidal dendrites are seen better using GKAP antibody N1564, whereas interneurons and their dendrites are labeled more strongly by C9589. This could be attributable to cell typespecific differences in GKAP protein-protein interactions, which may differentally affect accessibility of antibodies directed against distinct regions of the molecule.

In cerebral cortex (Fig. 5A), GKAP staining is found in all six cortical layers. Apical dendrites of pyramidal neurons and dendrites of nonpyramidal neurons show a punctate pattern of GKAP immunoreactivity suggestive of synaptic elements (Fig. $5 D-F)$. In the cerebellum, Purkinje cell bodies and proximal dendrites are stained. Granule cells show GKAP immunoreactivity on their surface and more prominently in the glomeruli of the granule cell layer (Fig. $5 B, C, G$ ). Scattered interneurons are lightly stained. This cellular distribution of GKAP immunoreactivity in cerebellum and neocortex is also consistent with the in situ hybridization findings (Fig. 3B,C).

\section{Immunogold electron microscopic localization of GKAP}

Electron microscopy reveals GKAP immunogold labeling mainly at synapses, although occasional dendrites are immunopositive. Synaptic staining is virtually exclusively at asymmetric (presumably excitatory) contacts and seems stronger at spines than on dendritic shafts. Figure $6 A-C$ show examples of immunolocalization of GKAP over the PSD of dendritic spines, although an occasional particle lies within the cytoplasm, possibly associated with cytoskeletal elements (Fig. $6 B$ ). Occasional dendritic profiles have high levels of cytoplasmic labeling (data not shown), perhaps corresponding to the strongly stained dendrites of interneurons seen by light microscopy (see Figs. 4, 5).

Quantitative EM analysis shows that GKAP immunogold particles are concentrated on the intracellular side of the postsynaptic membrane, at a mean distance of $23 \pm 2 \mathrm{~nm}$ from the postsynaptic membrane (Fig. 6D). Whereas material embedded in Epon-Spurr showed slightly higher levels of GKAP labeling than material embedded in Lowicryl, localization of gold particles in brain sections embedded in both plastics was similar. In the lateral plane (parallel to the synaptic cleft), GKAP seems to be distributed uniformly throughout the PSD up to a point close to the edge of the density (Fig. 6E). 

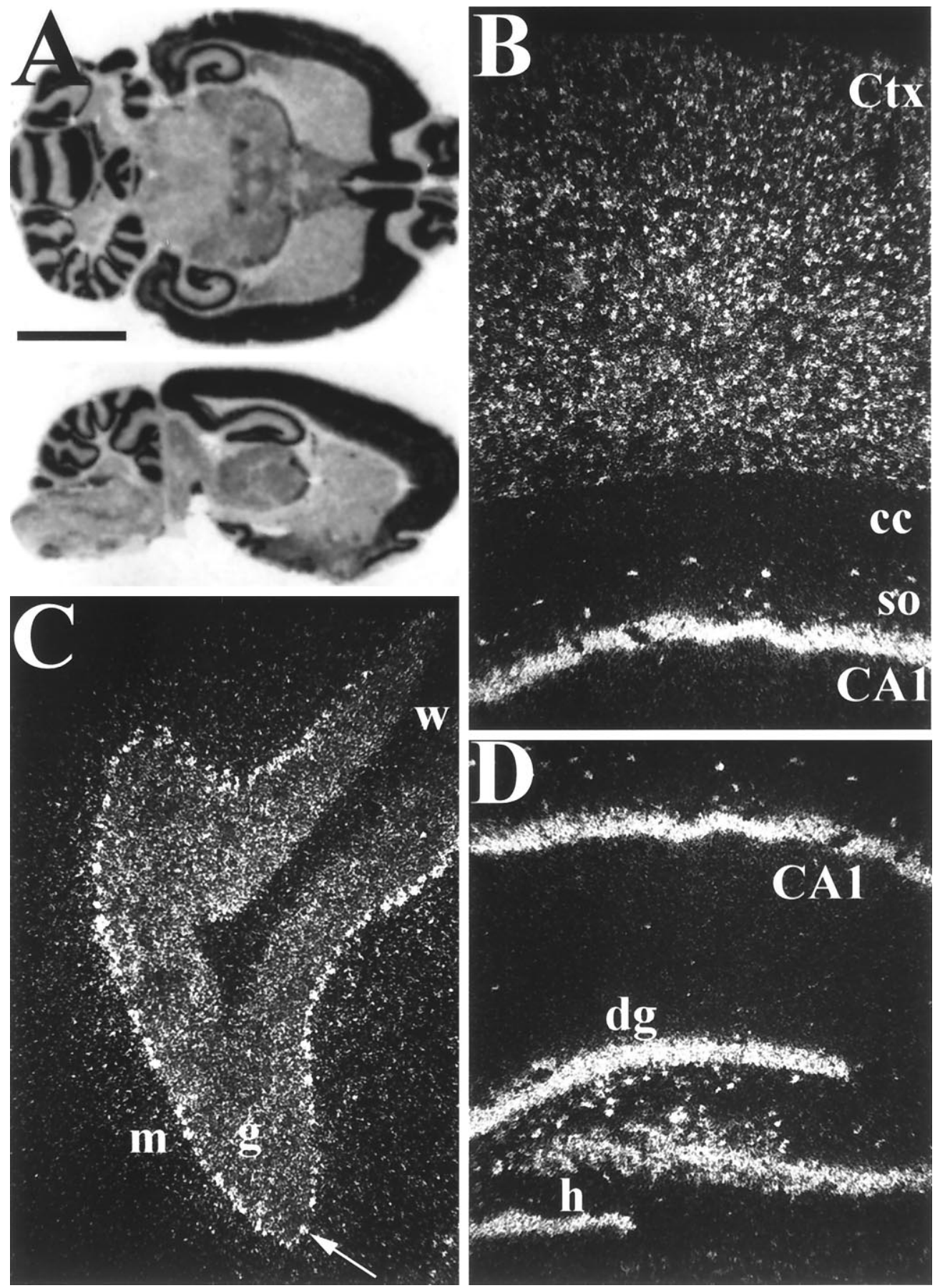

Figure 3. Distribution of GKAP mRNA in adult rat brain analyzed by in situ hybridization. A, Horizontal (top) and sagittal (bottom) rat brain sections probed with ${ }^{35} \mathrm{~S}$-labeled antisense GKAP cRNA. $B-D$, Dark-field microscopy of sagittal in situ hybridization sections. $B$, Hippocampal area CA1 and overlying cortex. Ctx, Cerebral cortex, so, st. oriens; $c c$, corpus callosum. $C$, Cerebellar cortex. The arrow points to a Purkinje cell. $m$, Molecular layer; $g$, granular layer; $w$, white matter. $D$, Hippocampal formation. $d g$, Dentate gyrus; $h$, hilus. Note prominent expression of GKAP mRNA by interneurons in the hilar region of the dentate gyrus and the st. oriens of CA1. Scale bars: $A, 5 \mathrm{~mm}$; $B-D, 0.3 \mathrm{~mm}$.

\section{Specific localization of GKAP in glutamatergic synapses of cultured hippocampal neurons}

Neurons typically have different types of synapses on the same dendrite. The light and electron microscopic studies suggest the presence of GKAP predominantly at excitatory synapses. To determine whether GKAP is specific for excitatory glutamatergic synapses, cultured hippocampal neurons were doublelabeled with GKAP and AMPA receptor GluR1 antibodies, or with GKAP and GABA $_{\mathrm{A}}$ receptor $\beta 2$ and $\beta 3$ subunit antibodies. GKAP immunoreactive puncta colocalize exactly with GluR1, both on dendritic shafts in GABAergic cells (data not shown) and on dendritic spines in pyramidal cells (Fig. 7A,B). However, GKAP does not colocalize with the $\mathrm{GABA}_{\mathrm{A}}$ recep- tor $\beta 2$ and $\beta 3$ subunits (Fig. 7C,D), a marker for GABAergic inhibitory synapses.

\section{DISCUSSION}

The identification of GKAP as a novel protein that binds to the GK domain of PSD-95 (Kim et al., 1997) represented a major step in our efforts to identify the specific components and protein-protein interactions that underlie the structure of the synapse. In this paper we characterize GKAP expression at the RNA and protein levels, including EM localization of GKAP in the PSD of asymmetric synapses. Furthermore, by double-labeling experiments in cultured hippocampal neurons, we show GKAP to be apparently specific for 
Figure 4. Immunohistochemical localization of GKAP protein in the hippocampus. $A-C$, Coronal sections were immunolabeled with GKAP antibody C9589, and visualized by DAB. A, Hippocampal formation. The dendritic fields of pyramidal neurons and dentate granule cells and a population of interneurons, are heavily labeled. $B$, Region CA1 of the hippocampus. Note the relative absence of staining in pyramidal cell bodies, and the darkly stained interneurons and their dendrites. The dendrites of pyramidal neurons in the st. radiatum and st. oriens are also labeled, st. oriens more strongly than st. radiatum. $C$, Hilar region of the dentate gyrus, filled with GKAP immunoreactive interneurons and dendrites. Note the relative absence of staining in the granule cell body layer. $D-G$, Coronal sections immunolabeled by GKAP antibody N1564 $(D-E)$, or C9589 $(F, G)$ followed by Cy3- or FITCconjugated secondary antibody, and visualized by confocal microscopy. $D$, CA1 st. radiatum. Dendrites of pyramidal neurons are decorated by striking GKAP puncta. There is very slight labeling of pyramidal cell bodies. $E, 2 \times$ magnification of the dendrites in $D . F$, An isolated interneuron in area CA1. $G$, Interneurons and their dendrites in the hilar region of the dentate gyrus, covered in bright GKAP immunoreactive puncta. $s r$, St. radiatum; other abbreviations as shown in Figure 3. Scale bars: $A, 0.5 \mathrm{~mm}$; $B, C, 125 \mu \mathrm{m} ; D, G, 60 \mu \mathrm{m} ; E, F, 30 \mu \mathrm{m}$.
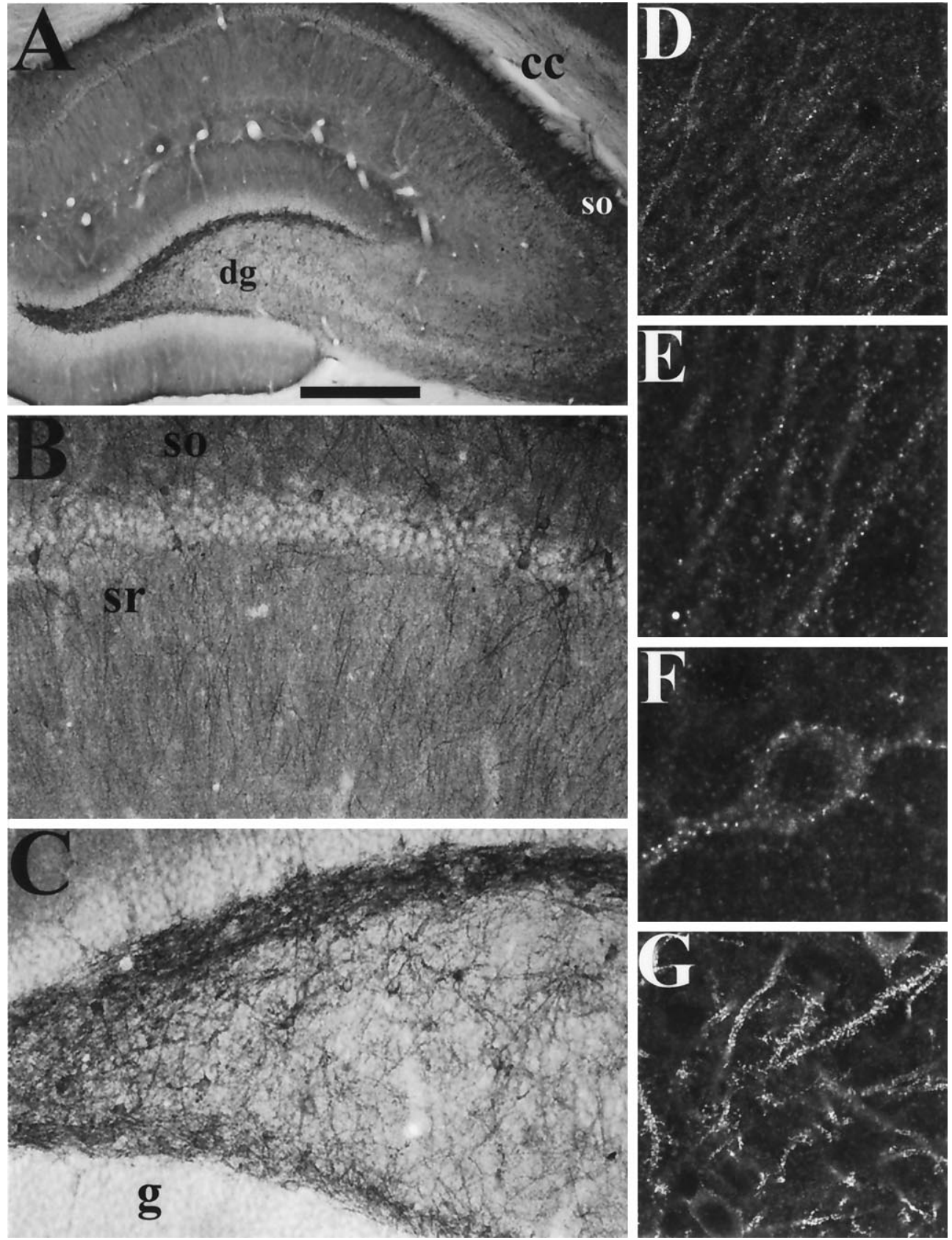

glutamatergic synapses. Both these lines of evidence indicate that GKAP is localized in excitatory rather than in inhibitory synapses. This specific localization is consistent with the direct association between GKAP and the PSD-95 family of proteins, which in turn interact specifically with the NMDA subclass of glutamate receptors. The specificity of GKAP for excitatory synapses illustrates that the molecular heterogeneity of synapses extends beyond the nature of the neurotransmitter and neurotransmitter receptor to include the proteins of the postsynaptic specialization. Presumably several distinct sets of proteins are involved in the organization of different classes of postsynaptic sites, as exemplified by the specific association of PSD-95/GKAP, gephyrin, and rapsyn with glutamatergic, glycinergic, and cholinergic synapses, respectively. It should be emphasized that GKAP is specifically localized in glutamatergic synapses, rather than specifically expressed in glutamatergic neurons, because GKAP, like GluR1 (Kharazia et al., 1996), is highly expressed in inhibitory interneurons as well as in glutamatergic neurons.

An important part of this study is the EM immunogold localization of GKAP. The higher resolution of this method allows us to localize GKAP in the PSD, within which there is a peak of GKAP labeling at 10-30 nm intracellular to the postsynaptic membrane. Considering the dimensions of the gold particles and $\mathrm{IgG}$ molecules, there is an expected error in the localization of labeling of approximately $\pm 10 \mathrm{~nm}$ (Matsubara et al., 1996). These errors should be unbiased, so the mean position of GKAP, $\sim 23$ $\mathrm{nm}$ from the postsynaptic membrane, should be considerably more accurate than this. However, given the PSD thickness of $\sim 40 \mathrm{~nm}$, it cannot be established from the present data whether GKAP molecules are concentrated in a narrow band of the PSD $\sim 20 \mathrm{~nm}$ from the plasma membrane, or are instead uniformly distributed throughout the thickness of the PSD. Either would be 


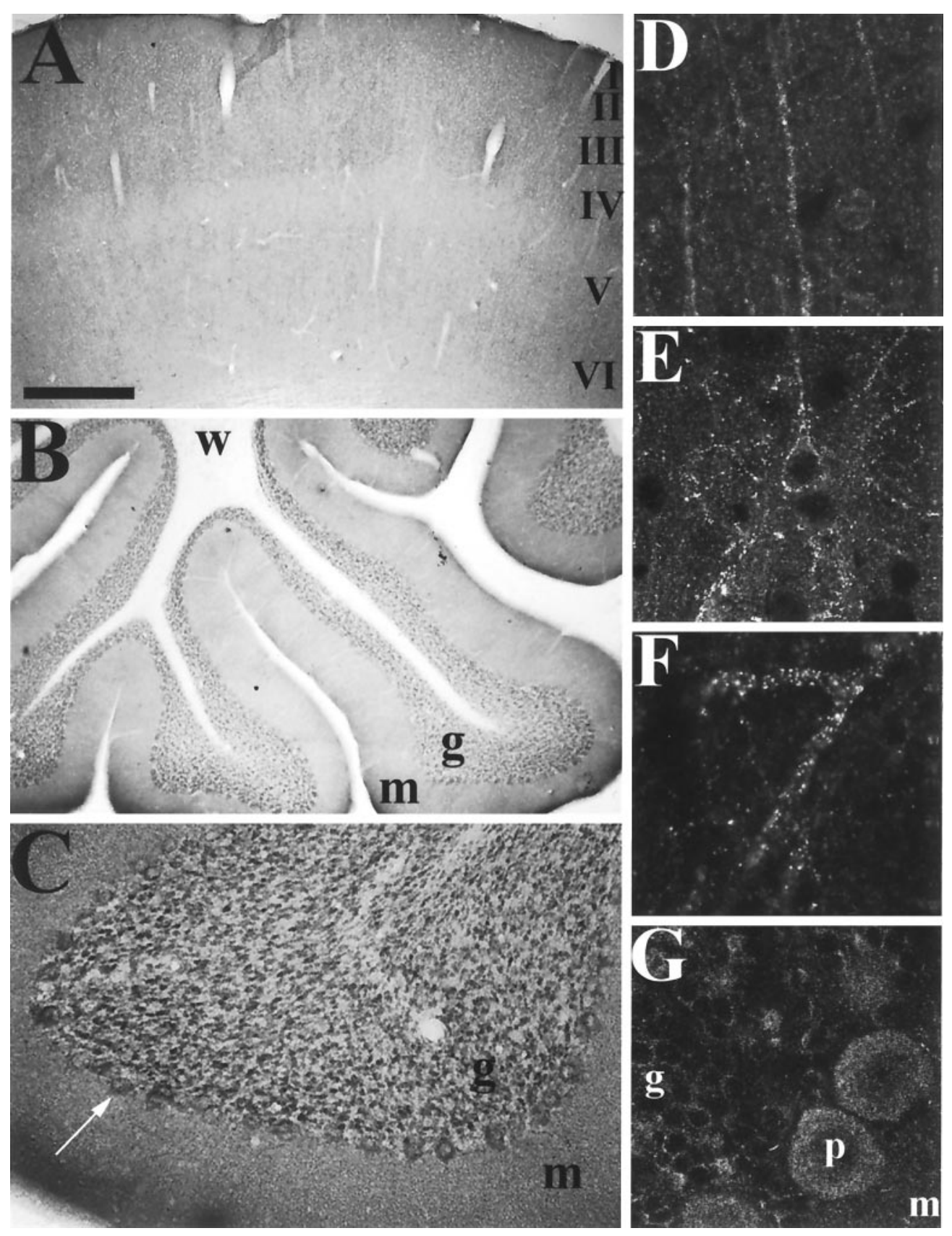

Figure 5. Immunohistochemical localization of GKAP protein in cerebral cortex and cerebellum. $A-C$, Coronal sections labeled with GKAP antibody C9589 and visualized via DAB histochemistry. $A$, Cerebral cortex, showing widespread and diffuse neuropil staining. $B, C$, Cerebellar Purkinje and granule cell staining in cerebellum. Purkinje cell bodies and glomeruli of the granular cell layer are stained. $D-G$, Sections labeled with GKAP antibody N1564 $(D)$ or C9589 $(E-G)$ and Cy3- or FITCconjugated secondary antibody and visualized by confocal microscopy. $D$, Apical dendrites of pyramidal neurons in cerebral cortex decorated by GKAP immunoreactive puncta. $E, F$, Bright GKAP puncta on dendrites of neocortical neurons. $G$, High-power view of the Purkinje cell layer in the cerebellum. $p$, Purkinje cell; other abbreviations as in Figure 3. Scale bars: $A, B, 0.5 \mathrm{~mm} ; C, 125$ $\mu \mathrm{m} ; D, E, G, 60 \mu \mathrm{m} ; F, 30 \mu \mathrm{m}$. consistent with the observed mean and distribution. Nevertheless, this GKAP immunogold distribution is distinct from that of NMDA receptor 1 (NMDAR1). NMDAR1 exhibits a similarly even "lateral" distribution along the active zone, but it lies considerably closer to the postsynaptic membrane (Kharazia et al., 1995). This differential subsynaptic distribution is consistent with GKAP being separated from NMDA receptors by PSD-95. Based on biochemical criteria, GKAP is a core component of the PSD (Kim et al., 1997), but its localization in the deeper part of the PSD places it in a position to potentially link PSD-95 to cytosolic signaling pathways or to cytoskeleton. Isolation of GKAPinteracting proteins may therefore yield interesting molecules that lie at the interface between PSD and the dendritic cytoplasm.

Although we conclude a predominantly postsynaptic localization for GKAP by LM and EM studies, a minor distribution of GKAP at other subcellular sites cannot be excluded. Indeed, occasional GKAP immunoreactivity was seen by EM in presynaptic and nonsynaptic sites. This is a pertinent issue because GKAP binds in vitro to the GK domains of all known members of the PSD-95 family (Kim et al., 1997), including SAP97, which has a presynaptic and axonal distribution (Müller et al., 1996). Whether GKAP or GKAP variants show differential association with the various members of the PSD-95 family in vivo remains to be determined.

Obviously, the most outstanding question regarding GKAP is one of function. It is widely expressed in the brain and localizes to the PSD in neurons, but what is the role of GKAP in synaptic structure or function? The known interaction of GKAP with the channel-clustering proteins of the PSD-95 family suggests some interesting possibilities. Perhaps GKAP is involved in the synaptic targeting of PSD-95 family members and their associated molecules (NMDA receptors, Shaker $\mathrm{K}^{+}$channels, and neuronal 

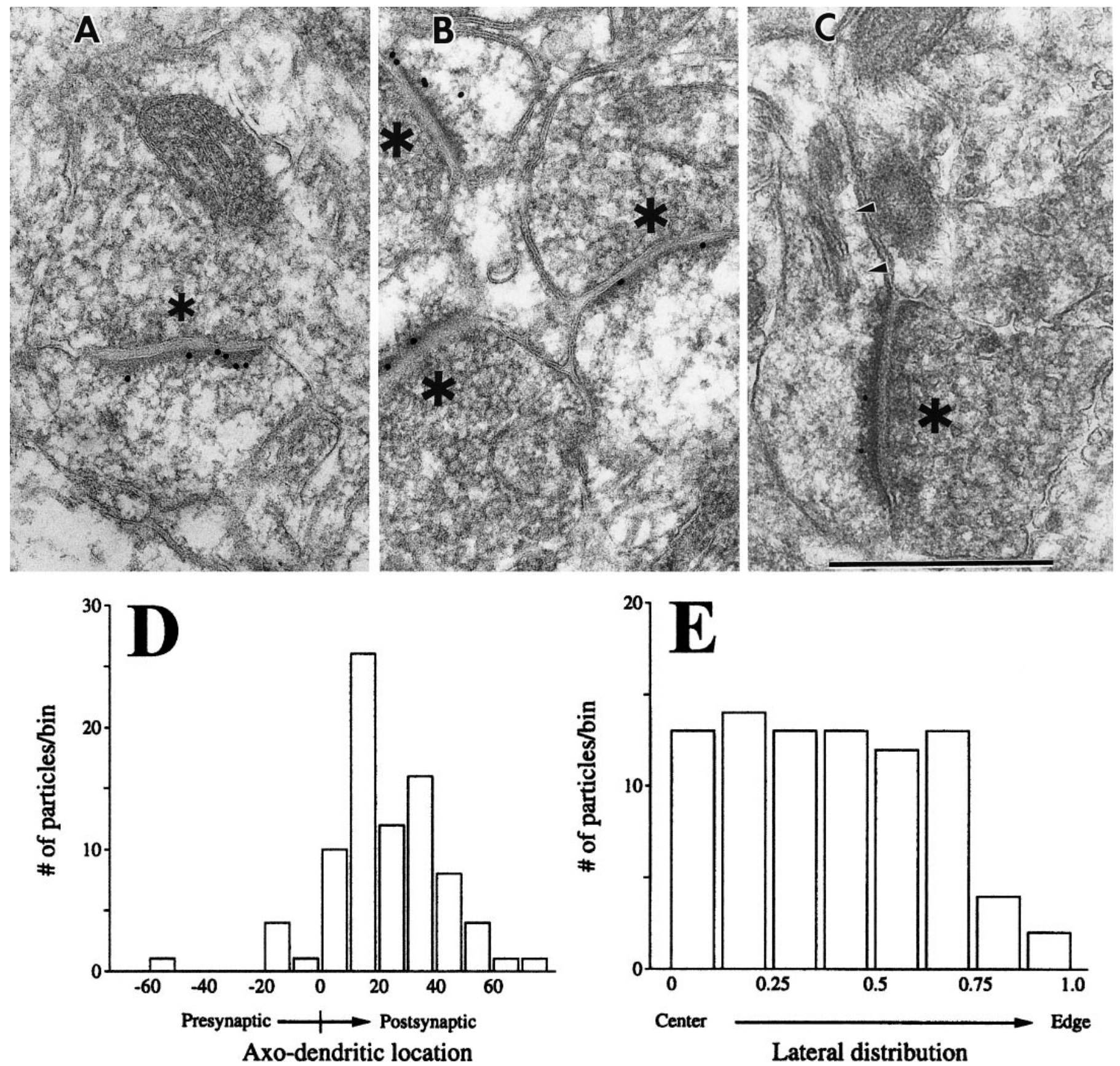

Figure 6. Immunogold EM localization of GKAP in dendritic spines and PSD. $A-C$, Postembedding $18 \mathrm{~nm}$ immunogold labeling of GKAP in sections from cerebral cortex layers II-III. *Presynaptic terminals. $A$, An asymmetric synapse showing gold particles associated with PSD; some particles lie against the plasma membrane, and others lie at the cytoplasmic face of the PSD. $B$, Three immunopositive synapses in the same field, each with gold particles overlying the PSD. One particle (just below the $B$ ) seems to lie within the cytoplasm, perhaps in association with a cytoskeletal element. $C$, An immunopositive spine cut in a longitudinal plane, permitting visualization of the spine apparatus (arrowheads) and spine neck. Scale bar, $500 \mathrm{~nm}$. $D-E$, Quantitative analysis of the distribution of GKAP immunogold particles at synapses. Grids of neocortex (layers II-III) prepared from two animals were examined. Random electron micrographs were made of fields in which at least one gold particle seemed associated with a synaptic active zone. EM negatives were digitized, and all gold particles within $100 \mathrm{~nm}$ of clearly definable active zones were analyzed. The data were from 85 active zones (mean length of synaptic apposition, $338 \mathrm{~nm}$; $\mathrm{SD}, 81 \mathrm{~nm}$ ). $D$, Distribution of gold particles across the synapse, axis perpendicular to the synaptic cleft (" 0 " corresponds to the cytoplasmic leaflet of the postsynaptic membrane). GKAP-immunogold distribution peaks at $10-30 \mathrm{~nm}$ on the intracellular side of the postsynaptic membrane. E, Lateral distribution of gold particles. Normalized lateral distance is defined as the absolute value of [(distance from center of particle to one edge of active zone) - (distance to other edge of active zone)]/(total length of active zone). GKAP is distributed evenly along the active zone.

NOS)? This seems unlikely to be an essential function, because a Dlg mutant missing most of the GK domain (allele v59), can still appropriately localize Shaker channels to synaptic sites (Tejedor et al., 1997). Because the GK domain of Dlg also binds to GKAP, this suggests that the GK domain (and by extrapolation, GKAP) is not essential for synaptic localization of Dlg. However, v59 mutants have abnormal postsynaptic morphology in the larval neuromuscular junction (Lahey et al., 1994; Guan et al., 1996) and 

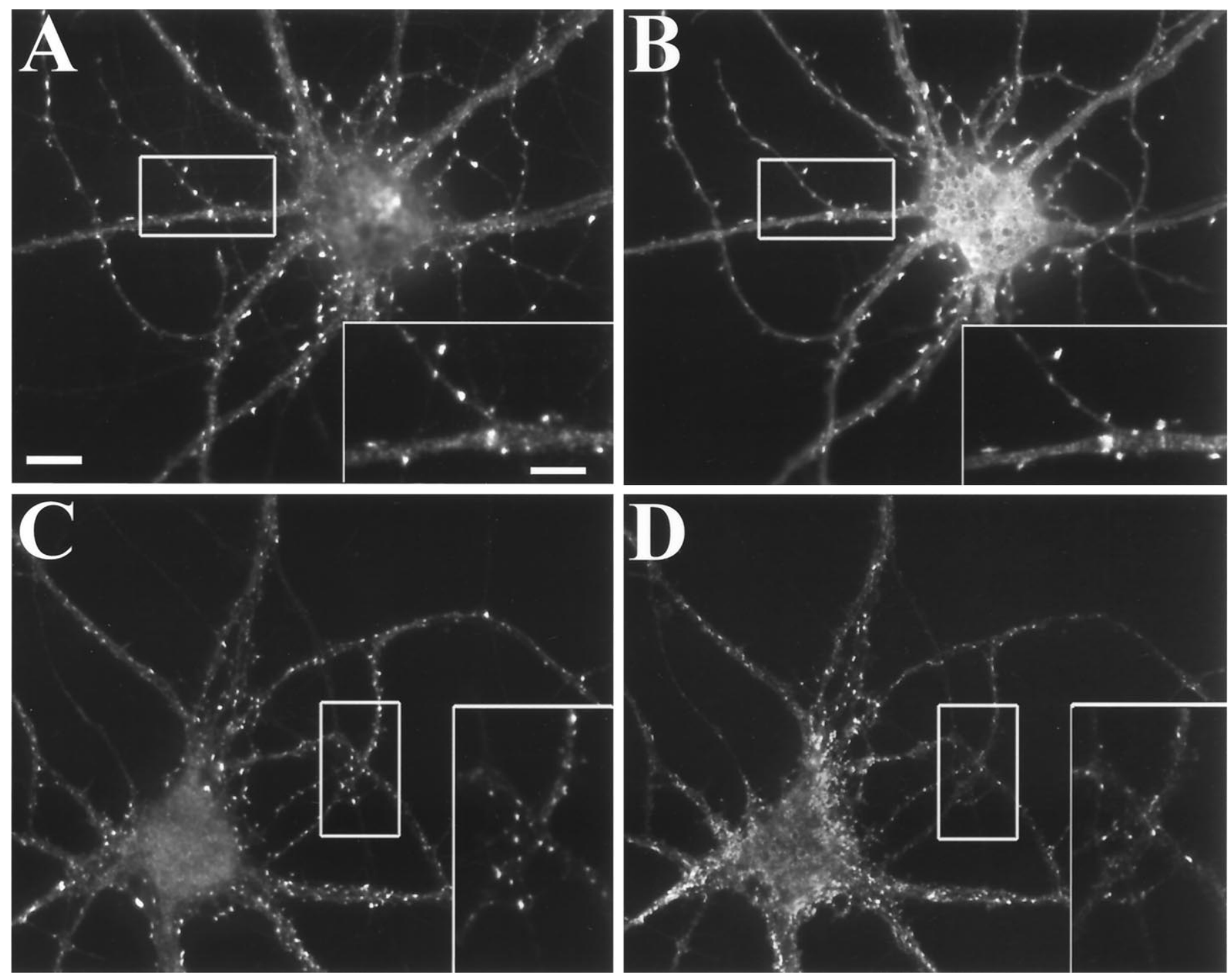

Figure 7. GKAP colocalizes at excitatory synapses with GluR1. In hippocampal neurons at 3 weeks in culture, GKAP $(A)$ is distributed in puncta that colocalize with clusters of GluR1 $(B)$ at dendritic spines in pyramidal cells. Punctate GKAP immunoreactivity $(C)$ does not colocalize with clusters of the GABA-R $\beta 2$ and $\beta 3$ subunits $(D)$, markers of GABAergic inhibitory synapses. Scale bar, $10 \mu \mathrm{m} ;$ inset, $5 \mu \mathrm{m}$.

exhibit neoplastic overgrowth of epithelial cells of imaginal disks (Woods and Bryant, 1991), suggesting that the GK domain, and proteins that interact with the GK domain, might more likely be involved in intracellular signaling pathways. The isolation of GKAP-interacting proteins, in combination with genetic or dominant negative approaches, will be necessary to clarify further the cell biological and physiological functions of GKAP.

The in vivo functions of GKAP may be somewhat heterogeneous, however, given the complex alternative splicing of the GKAP gene. In addition to splice variants noted previously (Kim et al., 1997), we have now identified a major N-terminal variant, $\mathrm{GKAP}_{\mathrm{L}}$, that adds an unusually large (298 amino acids and $\sim 35 \mathrm{kDa}$ ) extension to the GKAP described previously. The large $\mathrm{N}$-terminal extension is presumably important for the specific functions of $\mathrm{GKAP}_{\mathrm{L}}$, but unfortunately its primary sequence contains no region of homology to known proteins. Splice variant-specific probes and antibodies will be helpful to determine whether the various isoforms of GKAP are differentially expressed during development or in a cell type-specific manner. Such studies may yield clues to GKAP function and are underway.

Note added in proof. During review of this work, Takeuchi et al. (J Biol Chem 272:11943-11951, 1997) isolated several SAP90/ PSD-95 associated proteins, including an alternatively spliced isoform of GKAP/GKAP ${ }_{L}$, SAPAP1.

\section{REFERENCES}

Banker GA, Cowan WM (1977) Rat hippocampal neurons in dispersed cell culture. Brain Res 126:397-425.

Brenman JE, Chao DS, Gee SH, McGee AW, Craven SE, Santillano DR, Wu Z, Huang F, Xia H, Peters MF, Froehner SC, Bredt DS (1996a) Interaction of nitric oxide synthase with the postsynaptic density protein PSD-95 and $\alpha 1$-syntrophin mediated by PDZ domains. Cell 84:757-767.

Brenman JE, Christopherson KS, Craven SE, McGee AW, Bredt DS (1996b) Cloning and characterization of postsynaptic density 93, a nitric oxide synthase interacting protein. J Neurosci 16:7407-7415.

Cho K-O, Hunt CA, Kennedy MB (1992) The rat brain postsynaptic density fraction contains a homolog of the drosophila discs-large tumor suppressor protein. Neuron 9:929-942. 
Craig AM, Blackstone CD, Huganir RL, Banker G (1994) Selective clustering of glutamate and $\gamma$-aminobutyric acid receptors opposite terminals releasing the corresponding neurotransmitters. Proc Natl Acad Sci USA 91:12373-12377.

Froehner SC (1993) Regulation of ion channel distribution at synapses. Annu Rev Neurosci 16:347-368.

Guan B, Hartmann B, Kho Y-H, Gorczyca M, Budnik V (1996) The Drosophila tumor suppressor gene, $d l g$, is involved in structural plasticity at a glutamatergic synapse. Curr Biol 6:695-706.

Hall Z, Sanes JR (1993) Synaptic structure and development: the neuromuscular junction. Neuron 10:99-122.

Kharazia VN, Phend K, Wenthold R, Weinberg RJ (1995) Synaptic localization of AMPA \& NMDAR1 receptor subunits in rat cerebral cortex. Soc Neurosci Abstr 21:1837.

Kharazia VN, Wenthold RJ, Weinberg RJ (1996) GluR1-immunoreactive interneurons in rat neocortex. J Comp Neurol 368:399-412.

Kim E, Cho K-O, Rothschild A, Sheng M (1996) Heteromultimerization and NMDA receptor-clustering activity of chapsyn-110, a member of the PSD-95 family of proteins. Neuron 17:103-113.

Kim E, Naisbitt S, Hsueh Y-P, Rao A, Rothschild A, Craig AM, Sheng M (1997) GKAP, a novel synaptic protein that interacts with the guanylate kinase-like domain of the PSD-95/SAP90 family of channel clustering molecules. J Cell Biol 136:669-678.

Kim E, Niethammer M, Rothschild A, Jan YN, Sheng M (1995) Clustering of Shaker-type $\mathrm{K}^{+}$channels by interaction with a family of membrane-associated guanylate kinases. Nature 378:85-88.

Kistner U, Wenzel BM, Veh RW, Cases-Langhoff C, Garner AM, Appeltauer U, Voss B, Gundelfinger ED, Garner CC (1993) SAP90, a rat presynaptic protein related to the product of the Drosophila tumor suppressor gene $d l g$-A. J Biol Chem 268:4580-4583.

Kornau H-C, Schenker LT, Kennedy MB, Seeburg PH (1995) Domain interaction between NMDA receptor subunits and the postsynaptic density protein PSD-95. Science 269:1737-1740.

Lahey T, Gorczyca M, Jia X-X, Budnik V (1994) The Drosophila tumor suppressor gene $d l g$ is required for normal synaptic bouton structure. Neuron 13:823-835.

Lue RA, Marfatia SM, Branton D, Chishti AH (1994) Cloning and characterization of hdlg: the human homologue of the Drosophila discs large tumor suppressor binds to protein 4.1. Proc Natl Acad Sci USA 91:9818-9822.
Matsubara A, Laake JH, Davanger S, Usami S-I, Ottersen OP (1996) Organization of AMPA receptor subunits at a glutamate synapse: a quantitative immunogold analysis of hair cell synapses in the rat organ of corti. J Neurosci 16:4457-4467.

Matsumine A, Ogai A, Senda T, Okumura N, Satoh K, Baeg G-H, Kawahara T, Kobayashi S, Okada M, Toyoshima K, Akiyama T (1996) Binding of APC to the human homolog of the Drosophila discs large tumor suppressor protein. Science 272:1020-1023.

Müller BM, Kistner U, Veh RW, Cases-Langhoff C, Becker B, Gundelfinger ED, Garner CC (1995) Molecular characterization and spatial distribution of SAP97, a novel presynaptic protein homologous to SAP90 and the Drosophila discs-large tumor suppressor protein. J Neurosci 15:2354-2366.

Müller BM, Kistner U, Kindler S, Chung WJ, Kuhlendahl S, Lau L-F, Veh RW, Huganir RL, Gundelfinger ED, Garner CC (1996) SAP102, a novel postsynaptic protein that interacts with the cytoplasmic tail of the NMDA receptor subunit NR2B. Neuron 17:255-265.

Newman GR, Hobot JA (1993) Resin microscopy and on-section immuno-cytochemistry. Berlin: Springer.

Niethammer M, Kim E, Sheng M (1996) Interaction between the $C$-terminus of NMDA receptor subunits and multiple members of the PSD-95 family of membrane-associated guanylate kinases. J Neurosci 16:2157-2163.

Phend KD, Rustioni A, Weinberg RJ (1995) An osmium-free method of Epon embedment that preserves both ultrastructure and antigenicity for postembedding immunocytochemistry. J Histochem Cytochem 43:283-292.

Sheng M (1996) PDZs and receptor/channel clustering: rounding up the latest suspects. Neuron 17:575-578.

Standaert DG, Landwehrmeyer GB, Kerner JA, Penney Jr JB, Young AB (1996) Expression of NMDAR2D glutamate receptor subunit mRNA in neurochemically identified interneurons in the rat neostriatum, neoxortex, and hippocampus. Mol Brain Res 42:89-102.

Tejedor FJ, Bokhari A, Rogero O, Gorczyca M, Zhang J, Kim E, Sheng M, Budnik V (1997) Essential role for $d l g$ in synaptic clustering of shaker $\mathrm{K}^{+}$channels in vivo. J Neurosci 17:152-159.

Woods DF, Bryant PJ (1991) The discs-large tumor suppressor gene of Drosophila encodes a guanylate kinase homolog localized at septate junctions. Cell 66:451-464. 